University of Rhode Island

DigitalCommons@URI

Civil \& Environmental Engineering Faculty

Publications

Civil \& Environmental Engineering

2019

\title{
A microstructure-guided numerical approach to evaluate strain sensing and damage detection ability of random heterogeneous self-sensing structural materials
}

Sumeru Nayak

University of Rhode Island

Sumanta Das

University of Rhode Island, sumanta_das@uri.edu

Follow this and additional works at: https://digitalcommons.uri.edu/cve_facpubs

The University of Rhode Island Faculty have made this article openly available.

Please let us know how Open Access to this research benefits you.

This is a pre-publication author manuscript of the final, published article.

Terms of Use

This article is made available under the terms and conditions applicable towards Open Access

Policy Articles, as set forth in our Terms of Use.

Citation/Publisher Attribution

Nayak, S., \& Das, S. (2019). A microstructure-guided numerical approach to evaluate strain sensing and damage detection ability of random heterogeneous self-sensing structural materials. Computational Materials Science, 156, 195-205. doi: 10.1016/j.commatsci.2018.09.035

Available at: https://doi.org/10.1016/j.commatsci.2018.09.035

This Article is brought to you for free and open access by the Civil \& Environmental Engineering at DigitalCommons@URI. It has been accepted for inclusion in Civil \& Environmental Engineering Faculty Publications by an authorized administrator of DigitalCommons@URI. For more information, please contact digitalcommonsgroup@uri.edu. 


\title{
A Microstructure-guided Numerical Approach to Evaluate Strain Sensing and Damage Detection Ability of Random Heterogeneous Self-sensing Structural Materials
}

\author{
Sumeru Nayak ${ }^{1}$, Sumanta Das²* \\ ${ }^{1}$ Graduate Student, Civil and Environmental Engineering, University of Rhode Island, Kingston, RI \\ 02881, United States \\ $2^{2 *}$ Assistant Professor, Civil and Environmental Engineering, University of Rhode Island, Kingston, \\ RI 02881, United States, Email: sumanta das@uri.edu (corresponding author)
}

\begin{abstract}
Heterogeneous self-sensing materials that respond electrically to mechanical strains enable real time health monitoring of structures. To facilitate design and applicability of such smart materials with piezo-resistivity, a finite element-based numerical framework is being proposed in this paper for evaluation of electro-mechanical response and strain-sensing ability. Intrinsic heterogeneous nature of such composites warrants the need for microstructure-based study to have an insight into the effect of microstructural configuration on the macro-scale response. The microstructure-guided simulation framework, presented in this paper, implements interfacial debonding at the matrix-inclusion interface using a coupled interface damage-cohesive zone model and incorporates an isotropic damage model in the matrix under applied strain in the post-peak regime to obtain the deformed/damaged microstructure which is subjected to an electrical potential to simulate change in resistance due to applied strain. The applicability of the simulation framework is confirmed through its successful implementation on a smart structural material containing nano-engineered conductive coating at the inclusion-matrix interfaces. The predicted electro-mechanical responses correspond very well with the experimental observations and thus, the model has the potential to help develop design strategies to tailor the microstructure in these self-sensing materials for efficient performance.
\end{abstract}

Keywords: Piezo-resistivity; strain sensing; Cohesive zone model; continuum damage; microstructural model 


\section{INTRODUCTION}

Structural Health monitoring (SHM) provides valuable information on the reliability and safety of the structures and it can help develop strategies to save the structures before critical damage threatens the structural integrity [1,2]. Strain- and damage-sensing are integral aspects of SHM. Most of the loadbearing structures are very sensitive to damage and it can cause catastrophic failures leading to immense loss of life and property [1,3]. Therefore costly routine inspections have been used for maintenance of these structures. Traditionally, various non-destructive testing (NDT) techniques such as ultrasound testing, radiographic tests (X-ray) etc. have been used, although they are impractical and expensive for large structures. Thus, there has been a need for a real-time mixed global/local damage-sensing approach. For real-scale industrial structures, use of smart composites is gaining popularity in recent times for strainsensing in structures [4-6]. In particular, such smart composites achieve damage-sensing capability by utilizing piezoresistivity which is an electromechanical phenomenon that enables certain electrically conductive composites to respond electrically under the influence of strain [7-14]. Electrical resistance methods in these composites have been shown to be sensitive to minor and microscopic changes that include defects or damage $[10,14-16]$

Design of such smart materials requires a reliable numerical method that can predict electro-mechanical response at different length scales. This paper presents a comprehensive microstructure-guided electromechanical response prediction framework for a large class of smart heterogeneous materials using finite element modelling. In particular, the numerical framework is applied towards prediction of strain-sensing efficiencies in smart cementitious composites for infrastructure applications. In cement-based materials self-sensing capability has been achieved using carbon fibers, steel fibers and carbon nanotubes $[7,9,14,17]$. Although a variety of experimental studies $[8-15,18]$ report on electro-mechanical response of these systems under tension and compression, limited studies exist on prediction of strain-sensing and damage-detection efficiency in such self-sensing cementitious materials which is the primary goal of this research paper. The numerical simulation framework, presented in this paper, is developed for the first time in order to incorporate an applied strain range that encompasses both the elastic and the post-peak constitutive behavior thereby achieving both strain and damage sensing by electrical measurements in these cementitious matrices. The modelling scheme involves: (1) generation of representative microstructure of the heterogeneous composite using a stochastic packing algorithm; (2)application of periodic boundary conditions [19-23] in the representative unit cell to simulate a strain-controlled mechanical test scenario; (3) incorporation of interface damage to simulate interfacial debonding at the 
inclusion-matrix interface; (4) incorporation of an isotropic damage theory for damage in the matrix in the post-peak regime; (5) determination of effective constitutive behavior of the heterogeneous material; (6) re-meshing the deformed/damaged geometry corresponding to any specific applied strain and (7) determination of electrical response of the damaged/deformed microstructure. Steps 6 and 7 are performed for strains both in the elastic and the post-peak regime to obtain change in electrical responses for all the applied strains. The versatility of this approach is verified on a smart self-sensing cementitious material enabled by nano-engineered matrix-inclusion interface [24]. This smart material uses thin multi walled carbon nanotube (MWCNT)-based polymeric films at the matrix-inclusion interface $[15,16,24]$. Thus, this paper intends to demonstrate a numerical framework to evaluate the strain- and damagesensing efficiency of several heterogeneous materials facilitating microstructure-guided material design.

\section{NUMERICAL SIMULATION FRAMEWORK FOR ELECTRO-MECHANICAL RESPONSE EVALUATION AND DAMAGE DETECTION}

This section describes the framework which executes numerical simulation to evaluate electromechanical response of self-sensing materials using finite element analysis (FEA). Influence of damage and damage-sensing capability of the material is efficiently integrated into the simulation framework. Figure 1 summarizes the numerical simulation framework using a flowchart representation.

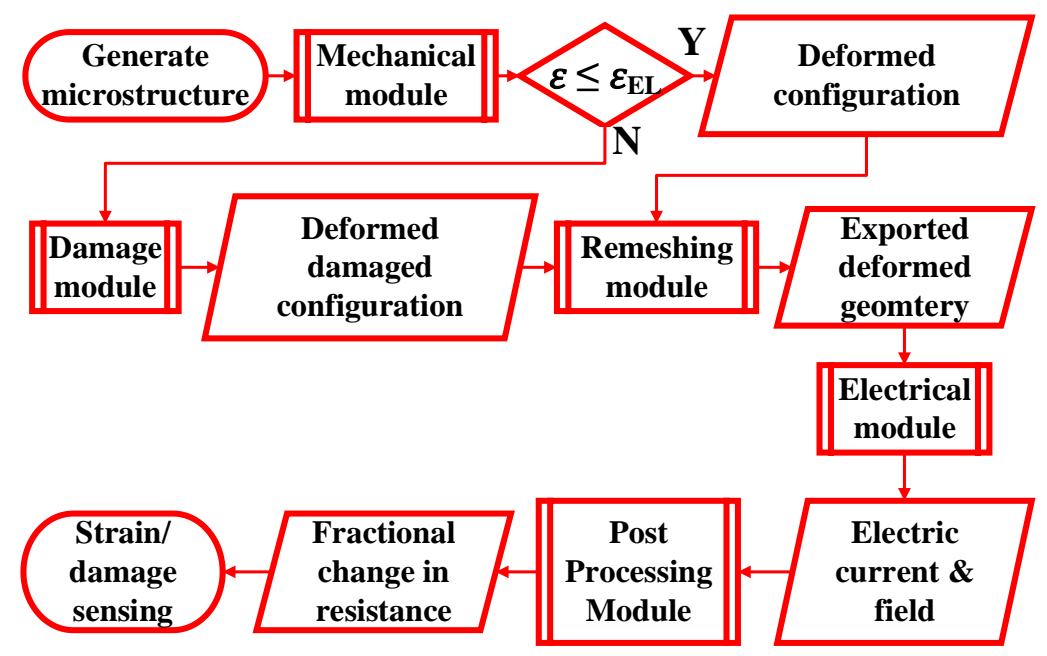

Figure 1: Flowchart of numerical simulation framework

The framework involves generation of a representative unit cell and evaluation of electromechanical responses implementing mechanical and electrical modules. The analysis framework is implemented here using a python script for ABAQUS ${ }^{\mathrm{TM}}$ solver. The mechanical module simulates a mechanical response of the unit cell under externally applied uniaxial strain and it accounts for interface damage at the matrix- 
inclusion interface. In addition, the mechanical module implements constitutive behavior of heterogeneous composites beyond the cracking strain (post-peak response) by implementing an isotropic damage model [25-27] in the matrix through a user-defined subroutine in ABAQUS ${ }^{\mathrm{TM}}$ [28-30]. An intermediate remeshing module imports the deformed configuration of the unit cell, obtained from the mechanical module and improves the quality of mesh before exporting the re-meshed unit cell to the electrical module as a starting geometry for the electrical analysis in order to achieve electro-mechanical response of the unit cell under applied strain. The electrical module obtains the deformed configuration of the unit cell from the remeshing module and obtains current distribution in the deformed unit cell under imposed electrical potential. Post processing of the relevant electrical responses in MATLAB (C) yields a homogenized change in electrical resistivity under different applied strains. Different components of the framework are detailed in the forthcoming sub-sections.

\subsection{Generation of Representative Unit Cells}

The unit cells are generated here using the Lubachhevsky-Stillinger algorithm [31-33]. This algorithm employs a hard contact model and hence particle overlaps are not allowed. First, the desired inclusions are randomly distributed inside the periodic bounding box with random initial velocities of the particles. The radius of each particle is first initialized as zero. The radius of $i^{\text {th }}$ particle $\left(r_{i}\right)$ in the next event is a function of the growth rate $\left(g_{i}\right)$, which is tailored to attain the desired particle size distribution shown in Equation 1.

$$
\frac{d r_{i}}{d t}=g_{i}
$$

Here $\mathrm{i}=1,2, \ldots \ldots$ is the number of particles. The growth rate between time $\mathrm{t}^{\mathrm{n}}$ and $\mathrm{t}^{\mathrm{n}+1}$ is computed using a finite difference scheme as follows.

$$
g_{i}=\frac{\left(r_{i}^{n+1}-r_{i}^{n}\right)}{\Delta t}
$$

Where $r_{i}^{n+1}$ and $r_{i}^{n}$ are radius at time $t^{n}$ and $t^{n+1}$ respectively and $\Delta \mathrm{t}=\left(t^{n+1}-t^{n}\right)$. The particle radii are then updated as follows for time $t^{n+1}$ by employing the growth rate and time increment $(\Delta \mathrm{t})$ as follows.

$$
r_{i}^{n+1}=r_{i}^{n}+g_{i} \Delta \mathrm{t}
$$

In addition, the position of particle ' $i$ ' at time $t^{n+1}$ i.e. $\mathbf{x}_{\mathrm{i}}^{\mathrm{n}+1}$ is updated considering a constant velocity $\left(\mathbf{v}_{\mathrm{i}}^{\mathrm{n}}\right)$ between the time nodes.

$$
\mathbf{x}_{\mathrm{i}}^{\mathrm{n}+1}=\mathbf{x}_{\mathrm{i}}^{\mathrm{n}}+\mathbf{v}_{\mathrm{i}}^{\mathrm{n}} \Delta \mathrm{t}
$$


The vector that connects the centers of particles ' $i$ ' and ' $j$ ' is obtained by subtracting the position vectors of the two particles.

$$
\mathbf{I}_{\mathrm{ij}}^{\mathrm{n}+1}=\mathbf{x}_{\mathrm{j}}^{\mathrm{n}+1}-\mathbf{x}_{\mathrm{i}}^{\mathrm{n}+1}
$$

The particles ' $\mathrm{i}$ ' and ' $\mathrm{j}$ ' are expected to be in contact if the sum of their radii is equal to the length of the connection vector. The time step size can be calculated as follows and the formulations are adequately detailed in [34].

$$
\Delta \mathrm{t}=\min \left[\frac{-\mathrm{v} \pm \sqrt{\mathrm{v}^{2}-\mathrm{uw}}}{\mathrm{u}}\right]
$$

where $\Delta t>0$ and $\mathrm{v}, \mathrm{u}$ and $\mathrm{w}$ are given as

$$
\begin{gathered}
\mathrm{v}=\mathbf{I}_{i j}^{n} \cdot\left[\mathbf{v}_{j}^{n}-\mathbf{v}_{i}^{n}\right]-\left[r_{i}^{n}+r_{j}^{n}\right]\left[g_{i}+g_{j}\right] \\
\mathrm{u}=\left[\mathbf{v}_{j}^{n}-\mathbf{v}_{i}^{n}\right]^{2}-\left[g_{i}+g_{j}\right]^{2} \\
\mathrm{w}=\mathbf{I}_{i j}^{n 2}-\left[r_{i}^{n}+r_{j}^{n}\right]^{2}
\end{gathered}
$$

Here, $\mathbf{v}_{i}^{n}$ and $\mathbf{v}_{j}^{n}$ are the velocities of particles ' $i$ ' and ' $j$ ' at time $t^{n} \cdot r_{i}^{n}$ and $r_{j}^{n}$ are the radius of particles ' $i$ ' and ' $j$ ' at time $t^{n}$. $g_{i}$ and $g_{j}$ are growth rates for particle ' $i$ ' and ' $j$ ' respectively. The vector connecting the position of the two particles at time $t^{n}$ is given as $I_{i j}^{n}=x_{j}^{n}-x_{i}^{n}$. The time step calculation (Equation 6) is performed for each particle pair that are being able to collide and thus minimum time step for all the possible collisions is adopted to move forward for the next event. All the particle positions $\mathbf{x}_{i}^{n+1}$ are updated using the forward Euler scheme (Equation 4) and new search for the next collision(s) is started. The post-contact velocities are computed as follows.

$$
v_{n_{i}}^{n+1^{+}}=\min \left\{v_{n_{i}}^{n+1^{-}}, v_{n_{j}}^{n+1^{-}}\right\}-g_{i} ; v_{n_{j}}^{n+1^{+}}=\max \left\{v_{n_{i}}^{n+1^{-}}, v_{n_{j}}^{n+1^{-}}\right\}+g_{i}
$$

Where $v_{n_{i}}^{n+1^{+}}$is the velocity after the contact and $v_{n_{i}}^{n+1^{-}}$is the velocity before the contact. Thus, all the above-mentioned steps are repeated and in the process of iterations the particles change position in the bounding box, collide and grow in order to obtain desired volume fraction. The algorithm is iterated until the target volume fraction of inclusions is reached. The algorithm is terminated as soon as the volume of the inclusions reaches the target volume fraction implying no further update on the relative positions or velocities of the particles. For the matrix, a homogenous solid section is generated, and the solid cut matrix is obtained by the difference of geometric areas of the solid matrix and the inclusions. Now, the solid cut matrix and inclusions are geometrically stitched at the boundaries to yield an inclusion embedded matrix geometry. Finally, the obtained microstructural information is implemented via a python language script to enable it to be imported to a commercial finite element software.

\subsection{Mechanical module}


The mechanical module implements periodic boundary conditions [35,36], meshes the unit cell, implements interfacial damage at the inclusion-matrix interface and incorporates isotropic damage in the matrix in the post-peak regime as described in the following sub-sections.

\subsubsection{Boundary condition}

Once the unit cell is generated, it is imported to the mechanical module. The mechanical module is summarized in Figure 2. The unit cell is first meshed using the python script and Periodic boundary conditions (PBC) [19-21] are applied. PBCs have been applied successfully towards FE analysis of random heterogeneous materials [37]. Periodic boundary conditions are shown to be computationally efficient even with smaller size of unit cells facilitating faster convergence [33]. PBC ensures displacement and traction continuity across the boundaries of neighboring unit cells. In $2 \mathrm{D}$, periodic microstructure the displacement field is given as follows.

$$
v_{i}\left(x_{1}, x_{2}\right)=\varepsilon_{i j}^{0} x_{j}+v_{i}^{*}\left(x_{1}, x_{2}\right)
$$

Here, $\varepsilon_{i j}^{0}$ is the applied strain tensor, and $v_{i}^{*}$ is a periodic function representing the modification of linear displacement field due to the heterogeneous microstructure. On a pair of parallel opposite boundary edges the displacements are given as follows.

$$
\begin{aligned}
& v_{i}^{s+}=\varepsilon_{i j}^{0} x_{j}^{s+}+v_{i}^{*} \\
& v_{i}^{s-}=\varepsilon_{i j}^{0} x_{j}{ }^{s-}+v_{i}^{*}
\end{aligned}
$$

Here, $s^{+}$and $s^{-}$are $s^{\text {th }}$ pair of two opposite parallel boundary surfaces of the unit cell. The periodic function $v^{*}$ is the same at both the parallel opposite edges due to periodicity. Subtracting 10b from 10a the difference in displacements on two parallel edges are obtained as follows.

$$
v_{i}^{s+}-v_{i}^{s-}=\varepsilon_{i j}^{0}\left(x_{j}^{s+}-x_{j}^{s-}\right)=\varepsilon_{i j}^{0} \Delta x_{j}^{s}
$$

$\Delta x_{j}^{s}$ is constant for an applied $\varepsilon_{i j}^{0}$. The strain is applied on the unit call using the system of equations through a reference point. The general form of system equations can be written as follows.

$$
v_{i}^{s+}-v_{i}^{s-}+v_{i}^{\text {dummy }}=0
$$


Such linear equations are implemented for all parallel face pairs in 3D unit cells. Strain is applied on the unit cell through the constraint equations to simulate a strain-controlled test scenario. More details on the PBC can be found in $[34,38]$.

\subsubsection{Incorporation of Interfacial Debonding}

The mechanical module incorporates interfacial debonding at the inclusion-matrix interface. The interfacial debonding is implemented here using a continuum damage model coupled with cohesive zone model (CZM) [39-41]. Here, a continuity in displacement is ensured by implementation of zero-thickness interface elements. Such zero-thickness interface elements have been implemented successfully to model relative slip or separation on a predetermined surface in $[42,43]$. The theoretical framework of CZM involves a phenomenological model of failure where the assumed fictitious micro-cracks in the cohesive zone can exhibit interactive stresses, thereby enabling application of traction-separation law [44,45]. The separation in the traction-separation law is characterized here using an equivalent interface opening $(\lambda)$. Here, $\lambda$ consists of positive normal displacement jump $\left\langle\llbracket u_{n} \rrbracket\right\rangle$ and tangential displacement jump $\llbracket u_{t} \rrbracket$ across the zero-thickness interfacial elements as shown in Equation 13.

$$
\lambda=\sqrt{\left\langle\llbracket u_{n} \rrbracket\right\rangle^{2}+\llbracket u_{t} \rrbracket^{2}}
$$

The characteristic value of equivalent interface opening, $\lambda_{0}$ denotes the limit beyond which the traction at any interface element decreases with increasing $\lambda$. When $\lambda<\lambda_{0}$, the equivalent traction $\sigma_{\mathrm{c}}$ is expressed using a penalty stiffness $\mathrm{K}_{\mathrm{p}}$ as follows.

$$
\sigma_{\mathrm{c}}=\mathrm{K}_{\mathrm{p}} \lambda
$$

when $\lambda \geq \lambda_{0}$, the following relationship is implemented $[43,46]$.

$$
\sigma_{c}=f_{t} \exp ^{\frac{-f_{t}\left(\lambda-\lambda_{0}\right)}{G_{F}}}
$$

Where $f_{t}$ is the tensile strength and $G_{F}$ is the total fracture energy. $\lambda_{0}=\frac{2 G_{f}}{f_{t}}=\frac{f_{t}}{K_{P}}$ Where initial fracture energy, $\mathrm{G}_{f}=\frac{K_{I C}^{2}}{E}, K_{I C}$ is the mode-I fracture toughness and $E$ is the Young's modulus.

The equivalent traction is integrated over the volume to obtain the potential $\phi$, the partial derivatives of which with respect to normal and tangential components of the displacement jump yield the normal traction $t_{c n}$ and tangential traction $t_{c t}$ respectively as shown in Equation 15. 


$$
\boldsymbol{t}_{c}=\left(\begin{array}{c}
t_{c n} \\
t_{c t}
\end{array}\right)=\left(\begin{array}{c}
\frac{\partial \phi}{\partial \llbracket u_{n} \rrbracket} \\
\frac{\partial \phi}{\partial \llbracket u_{t} \rrbracket}
\end{array}\right)
$$

The mechanical tangent material matrix $\mathrm{C}_{c}^{u}$ can be expressed as partial derivatives of the resulting traction with respect to displacement jump as shown in Equation 16.

$$
\mathrm{C}_{c}^{u}=\left[\begin{array}{ll}
\frac{\partial t_{c n}}{\partial \llbracket u_{n} \rrbracket} & \frac{\partial t_{c n}}{\partial \llbracket u_{t} \rrbracket} \\
\frac{\partial t_{c t}}{\partial \llbracket u_{n} \rrbracket} & \frac{\partial t_{c t}}{\partial \llbracket u_{t} \rrbracket}
\end{array}\right]
$$

It should be noted here that the above formulations are applied for tension, when the interface opening in the normal direction is positive. In case of compression the normal interface compressive pressure is given as follows.

$$
\mathrm{t}_{\mathrm{cn}}=\mathrm{K}_{\mathrm{p}} \llbracket u_{n} \rrbracket
$$

Therefore, the mechanical tangent material matrix can be expressed as follows.

$$
\mathrm{C}_{c}^{u}=\left[\begin{array}{cc}
\mathrm{K}_{\mathrm{p}} & 0 \\
0 & \frac{\partial t_{c t}}{\partial \llbracket u_{t} \rrbracket}
\end{array}\right]
$$

The tangent material matrix $\mathrm{C}_{c}^{u}$ is transformed to the local co-ordinate system to obtain stiffness matrix of each cohesive element. While the penalty stiffness governs the traction-separation law with increase in $\lambda$ when $\lambda<\lambda_{0}$, the mechanical stiffness matrix is modified at every iteration with increasing $\lambda$ based on phenomenological damage model when $\lambda \geq \lambda_{0}$. Damaged mechanical stiffness matrix for interface elements obtained is used as the initial stiffness of the cohesive elements in the next step with increment in $\lambda$. Here, progressive debonding has been characterized with increasing $\lambda$ using a scalar interface damage parameter $D_{c}$ which is defined as follows.

$$
D_{c}=\frac{\lambda}{\lambda_{c r}}
$$

Where $\lambda_{c r}$ corresponds to equivalent interface opening at very low traction values in the post-peak regime of the traction-separation behavior, generally computed at $0.1 f_{t}$ in the post-peak regime [43]. The numerical simulation of the CZM extended damage model, as explained above, is implemented here using user-defined subroutine in ABAQUS ${ }^{\mathrm{TM}}$ and it requires initial fracture energy $\left(\mathrm{G}_{f}\right)$, total fracture energy $\left(G_{\mathrm{F}}\right)$ and tensile strength of matrix $\left(f_{t}\right)$ as input [47].

\subsubsection{Damage in the matrix}


In order to incorporate damage in the matrix in the post-peak regime, a damage module is incorporated inside the mechanical module. A continuum damage model is implemented here in the matrix once the applied strain exceeds the elastic limit $\left(\varepsilon_{E L}\right)$. Assuming isotropic stiffness degradation, the damage variable, $D$ is given as $[25-27,48]$ follows.

$$
\sigma=(1-D) C: \varepsilon
$$

Where the effective stress tensor is denoted by $\sigma, \mathrm{C}$ denotes fourth order tensor of elasticity and $\varepsilon$ is the strain tensor. The value of damage, $D$ ranges from 0 (undamaged) to 1 (completely damaged). The damage rate denoted by $\dot{D}$ assumes only zero or positive values which can be explained by its proportionality with the damage energy release rate [25]. The overall damage $D$ is a weighted sum of its tensile and compressive parts $\left(D_{t}\right.$ and $\left.D_{c}\right)$ that addresses the difference in tensile and compressive behavior of heterogeneous materials as shown in Equation $21[25,26]$.

$$
D=\alpha_{t} D_{t}+\alpha_{c} D_{c}
$$

For uniaxial tension value, of the parameter $\alpha_{t}$ becomes 1 and the parameter $\alpha_{c}$ becomes zero whereas the values of the parameters $\alpha_{t}$ and $\alpha_{c}$ are taken as zero and 1 respectively for uniaxial compression [25]. A non-local equivalent strain $\tilde{\varepsilon}$ is used to obtain the tensile and compressive damage, $D_{t}$ and $D_{c}$ respectively which is defined as follows $[25,48]$.

$$
\tilde{\varepsilon}=\sqrt{\sum_{i}<\varepsilon_{i}>_{+}^{2}}
$$

Where $\left\langle\varepsilon_{i}\right\rangle_{+}$is the positive part of the principal strain. The damage $D_{t}$ and $D_{c}$ evolve as a function of $\tilde{\varepsilon}$ as per the Equation 23-a and 23-b follows [25-27,48,49].

$$
\begin{gathered}
D_{t}(\tilde{\varepsilon})=1-\frac{\varepsilon_{D_{0}}\left(1-A_{t}\right)}{\tilde{\varepsilon}}-\frac{A_{t}}{\exp \left[B_{t}\left(\tilde{\varepsilon}-\varepsilon_{D_{0}}\right)\right]} \\
D_{c}(\tilde{\varepsilon})=1-\frac{\varepsilon_{D_{0}}\left(1-A_{c}\right)}{\tilde{\varepsilon}}-\frac{A_{c}}{\exp \left[B_{c}\left(\tilde{\varepsilon}-\varepsilon_{D_{0}}\right)\right]}
\end{gathered}
$$

Where $\varepsilon_{D_{0}}$ is damage initiation threshold (the ratio of tensile strength to the Young's modulus for quasibrittle materials). The model can be fitted to experimentally obtained uniaxial tensile and compressive constitutive response of various matrices to obtain corresponding values for the parameters $\varepsilon_{D_{0}}, A_{t}, B_{t}$, $A_{c}$ and $B_{c}$. The material continuum damage is implemented here using user defined subroutine in 
ABAQUS $^{\mathrm{TM}}$ [30]. The mechanically deformed/damaged geometry thus obtained is exported to re-meshing module to improve the quality of mesh as explained in the forthcoming section.

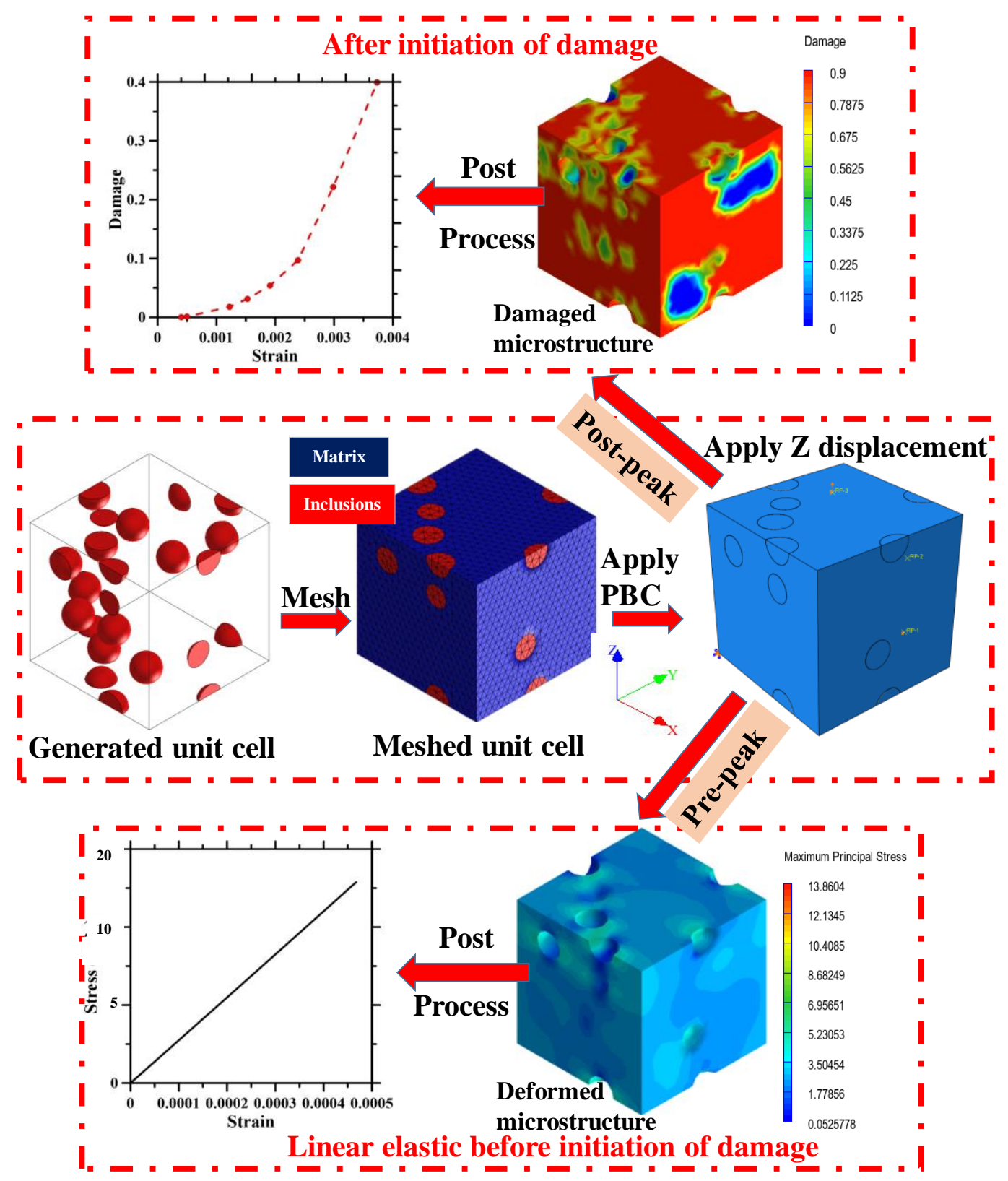

Figure 2. Schematic representation of the mechanical module

\subsection{Intermediate Re-meshing Module}

The deformed or damaged geometry of the unit cell, obtained from mechanical module, is re-meshed using this intermediate module. This module implements remeshing using a MATLAB subroutine. The subroutine operates on the deformed geometry and performs re-meshing/ mesh-refinements wherever 
the aspect ratio of the elements exceeds 3. The remeshing module, thus improve the quality of mesh in the deformed/damaged unit cell. The re-meshed deformed or damaged unit cell is then exported to the electrical module for electrical analysis.

\subsection{Electrical module}

The electrical module imports the deformed and re-meshed unit cell and assigns electrical properties to the component phases. In order to characterize the electrical response of the damaged unit cell, the damaged elements in the matrix are modeled with an electrical conductivity that decreases proportionally with the mechanical damage variable D. The electrical conductivity of the damaged elements $\left(\sigma_{i}\right)$ can be expressed in terms of the initial conductivity $\left(\sigma_{i-1}\right)$ as follows.

$$
\sigma_{i}=(1-\mathrm{D}) \sigma_{i-1}
$$

Similar relationships have been successfully implemented for thermal analyses coupled with mechanical damage elsewhere $[43,50]$. At every state of progressive damage, the conductivity is reduced proportional to the damage variable D. As the material damages fully, the simulation framework theoretically assumes an infinite resistance. In order to characterize the electrical behavior of the mechanical damage on the inclusion-matrix interface, the interface elements where the interface damage variable $\left(D_{c}\right)$ reaches 1 , are considered a perfect resistor with infinitely high electrical resistance.

After assignment of material properties, boundary conditions are incorporated. All other faces except the ones perpendicular to $\mathrm{Y}$ axis are insulated as can be seen in Figure 3. A unit potential is applied across the microstructure in the $Y$ direction as shown in Figure 3. The electrical module computes current density $(\bar{U})$ from the input electrical conductivity $(\sigma)$ of component phases and the applied electric field $(\bar{E})$ using Ohm's Law $(\bar{J}=\sigma \bar{E})$. The simulation yields the electric field and current density distribution in the unit cell which when volumetrically averaged by a post-processing module yields the average electrical conductivity as per Equation 25 [51,52].

$$
\sigma=\frac{\bar{J}}{\bar{E}}
$$

For a comparative representation, the average electrical conductivities $(\sigma)$ are expressed in terms of the fractional change in resistance (FCR) which is the ratio of the change in resistance $(\Delta R)$ and the bulk resistance of mechanically undeformed microstructure $\left(R_{0}\right)$ as shown in Equation 26 [51].

$$
F C R=\frac{\Delta R}{R_{0}}=\frac{\sigma_{0}}{\sigma}-1
$$


Where $\sigma_{0}$ is the conductivity response of the mechanically undeformed microstructure. In order to characterize the electrical response of the damaged microstructure, the damaged elements are modeled as insulators as explained earlier. The additional resistivity thus imparted to the overall microstructure leads to a different trend in FCR plotted with strain beyond the elastic limit.

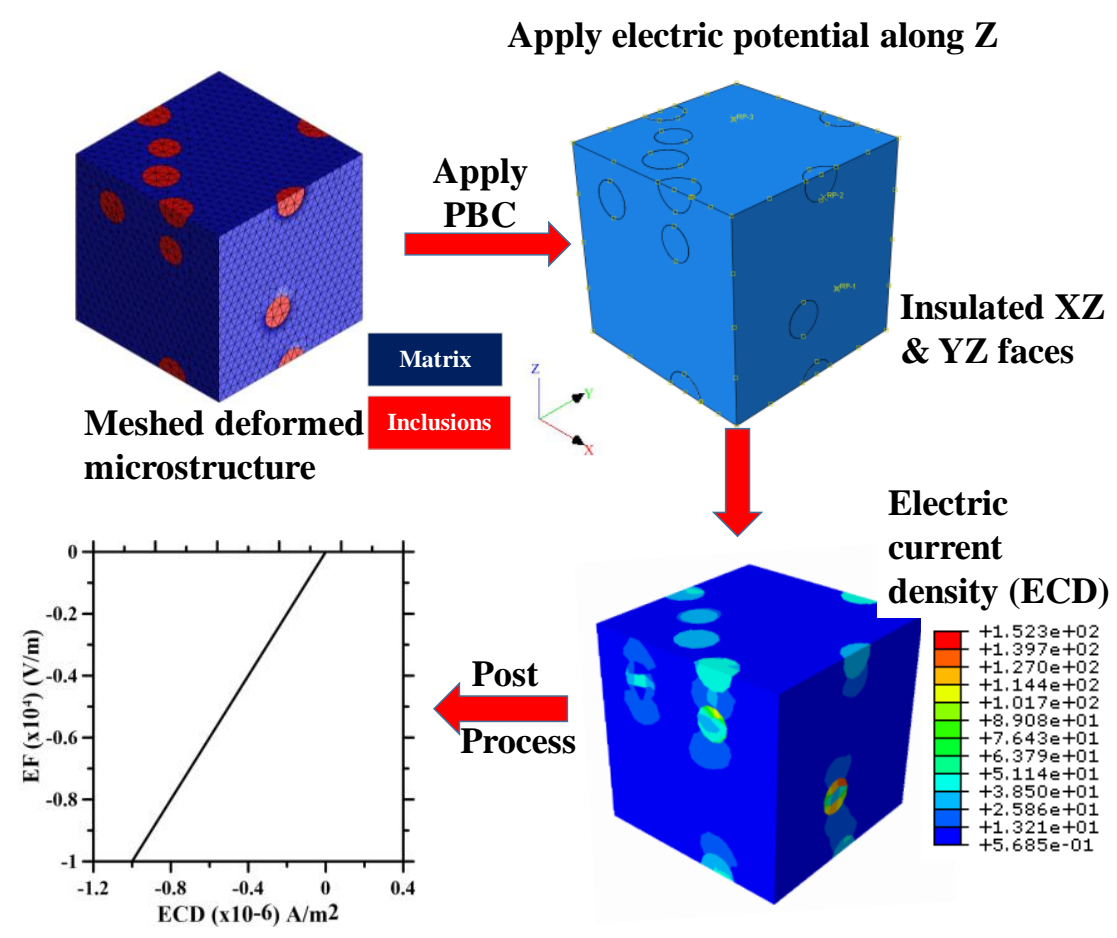

Figure 3. Schematic representation of the electrical module

The microstructure guided electro-mechanical simulation can be performed at different length scales so as to obtain macro-scale electro-mechanical response of heterogeneous smart materials. The numerical simulation framework, presented herein, can be used towards prediction of macroscopic electromechanical response of several random heterogeneous smart materials facilitating microstructure-guided material-design. In the forthcoming section, the numerical prediction scheme is applied to a smart cementitious material enabled by a nano-engineered matrix-inclusion interface to evaluate the effectiveness of the modelling framework.

\section{APPLICATION OF THE MODEL TO A SMART STRUCTURAL MATERIAL CONTAINING NANO- ENGINEERED INCLUSION-MATRIX INTERFACES}

This section describes the application of the aforementioned framework to a smart self-sensing cementitious material enabled through a nano-engineered cement-aggregate interface $[16,24]$. Such 
conductive coatings contain carbon nanotube (CNT) based thin latex films, the synthesis and application procedure of which is discussed in detail in $[15,53]$. These films are deposited on sand via airbrushing thus enabling a higher degree of dispersion in the composite matrix of the composite with a lesser carbon content than conventional CNT dispersion techniques [24,54]. Such conductive coatings are experimentally shown to be extremely effective in self-sensing applications [16,24]. The forthcoming subsections apply the electro-mechanical simulation framework to elucidate the influence of interfacial debonding, electrical conductivity and thickness of coating for a compressive understanding. In addition, this section also compares the numerical simulation results, obtained from the simulation framework for the smart self-sensing cementitious material with the experimental results reported in [16] with a view to validate the simulation framework.

\subsection{Influence of conductive coating on the strain sensing and damage detection capability}

As explained earlier, the mechanical module is first initiated which generates the unit cell using Lubachhevsky-Stillinger algorithm $[31,32,55]$, meshes the unit cell, applies periodic boundary conditions and implements a displacement-controlled simulation to obtain the deformed unit cell. Here, the volume fraction of sand is $45 \%$ [16]. The generated unit cell is shown in Figure $4(a)$. Sand particles $\left(d_{50}\right.$ is $600 \mu \mathrm{m}$ [56]) are dispersed in the unit cell of edge length $3 \mathrm{~mm}$. Based on a sensitivity study, the edge length of unit cell is adopted here as five times the mean diameter of sand particles beyond which any increase in the size of the unit cell results in insignificant change in the results. Similar relative size of unit cell with respect to size of inclusion has been successfully applied to evaluate micromechanical responses of cementitious composites in $[33,37]$. An absolute thickness of $10 \mu \mathrm{m}$ of the conductive coating is adopted in this study unless varied to evaluate the influence of coating thickness. A thickness of $10 \mu \mathrm{m}$ has been shown to yield an electrically conducting composite in [15]. This study also considers interfacial transition zone (ITZ) around the sand particles. The thickness of ITZ is considered to be $20 \mu \mathrm{m}$ [57-59]. In order to implement interfacial debonding zero-thickness interfacial elements are implemented at the conductive coating-ITZ interface (refer to section 2.2.2). The unit cell is finely meshed using CPE4R elements in ABAQUS ${ }^{T M}$. A mesh-sensitivity study was performed and a mesh containing 362137 CPE4R elements (in ABAQUS ${ }^{T M}$ ) yielded converged solution. The converged mesh is shown in Figure 4(b). Here 2D unit cells are considered instead of 3D as a tradeoff between computational efficiency and demand. Similar 2D unit cells are successfully adopted for cementitious materials in $[33,56]$. 


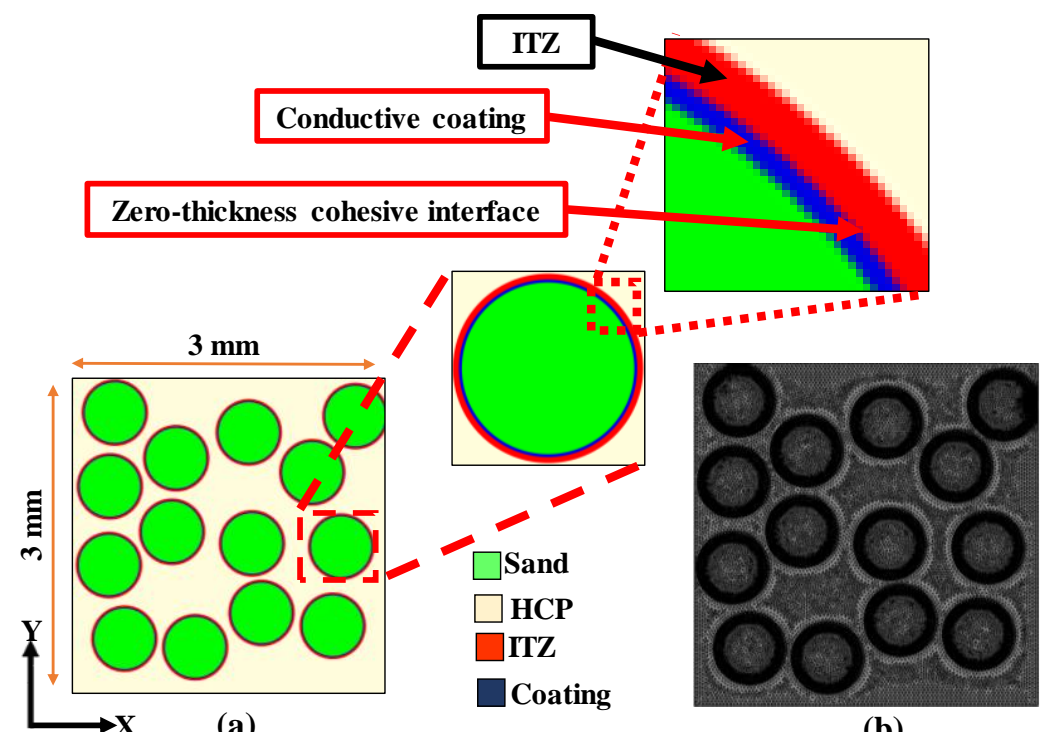

(b)

Figure 4. (a) generated microstructure with the coated sand particles dispersed in hardened cement paste (HCP) matrix and (b) meshed microstructure

The mechanically deformed configuration, obtained from mechanical module, is imported to the remeshing module where the deformed geometry is re-meshed ensuring a good quality (aspect ratio $\leq 3$ ) of elements [60-62]. The re-meshed unit cell is imported to electrical module for electrical analysis. The electrical module implements insulation at the edges parallel to y axis and applies a unit potential difference to obtain electric current distribution (ECD) and electric field in the unit cell. The post processing module computes the fractional change in resistance as explained earlier. The input material properties, shown in Table 1, are adopted from [15,51,56,59,63-67].

Table 1. The input material properties: Young's modulus (E), Poisson's ratio $(v)$ and electrical conductivity $(\sigma)$

\begin{tabular}{cccc}
\hline Phases & $\begin{array}{c}\mathrm{E}(\mathrm{GPa}) \\
{[56,65,68]}\end{array}$ & $\begin{array}{c}v \\
{[56,65,68]}\end{array}$ & $\begin{array}{c}\sigma(\mathrm{S} / \mathrm{m}) \\
{[51,63,64,67,69,70]}\end{array}$ \\
\hline HCP & 20 & 0.2 & 0.002 \\
Sand & 70 & 0.17 & $1.00 \mathrm{E}-08$ \\
Coating & 3.4 & 0.4 & 1000 \\
ITZ & 10 & 0.2 & 0.002 \\
\hline
\end{tabular}




\subsubsection{Consideration of interfacial debonding}

The mechanical module implements a continuum damage model coupled with cohesive zone model (CZM) at the zero-thickness interfacial elements in between the conductive coating and the ITZ, as explained earlier, to simulate debonding at the cement paste-coated aggregate interface under tensile strains. The traction-separation law is defined by tensile strength $\left(f_{t}\right)$, total fracture energy $\left(G_{F}\right)$ and initial fracture energy $\left(G_{f}\right)$ as explained earlier in section 2.2.2. Values of these parameters, adopted in this simulation are $2.7 \mathrm{MPa}, 25 \mathrm{~N} / \mathrm{m}$ and $19 \mathrm{~N} / \mathrm{m}$ respectively as reported in [71-73]. It should be noted that values of these parameters for the interface elements are considered same as the HCP matrix in this study due to lack of data. Debonding subroutine is implemented as explained in section 2.2.2 and values of scalar interface damage parameter $\left(D_{c}\right)$ are obtained for the zero-thickness cohesive interface elements. The electrical module assigns insulation behavior at the interface elements where the value of $D_{c}$ reaches 1.

Figures 5(a-1), (a-2) and (a-3) plot the interface damage parameter, $D_{c}$ (Equation 19) in the zero-thickness interfacial elements under applied strain of $0 \%, 0.00075 \%$ and $0.0161 \%$ respectively whereas Figures $5(b$ 1), (b-2) and (b-3) show the corresponding electric current densities under applied unit electrical potential. The figures suggest that the debonding areas increase progressively with increase in strain. Consequently, the electric current densities at the conductive coating gets altered resulting in change in the characteristics of the electrical response in the unit cell. Figures $5(b-1),(b-2)$ and (b-3) show overall reduction in the current density with progressive debonding and deformation due to increase in applied strain. Enlarged views of a sand particle under these strains also reveal alteration of ECD in the conductive coating with progressive interfacial debonding resulting in change in resistance and thereby change in FCR. 


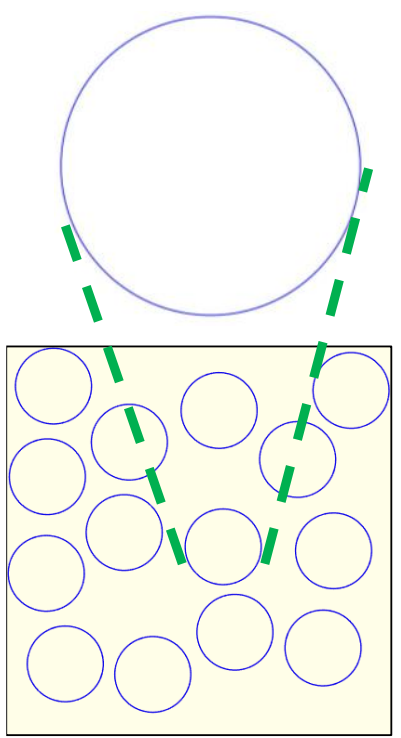

(a-1)
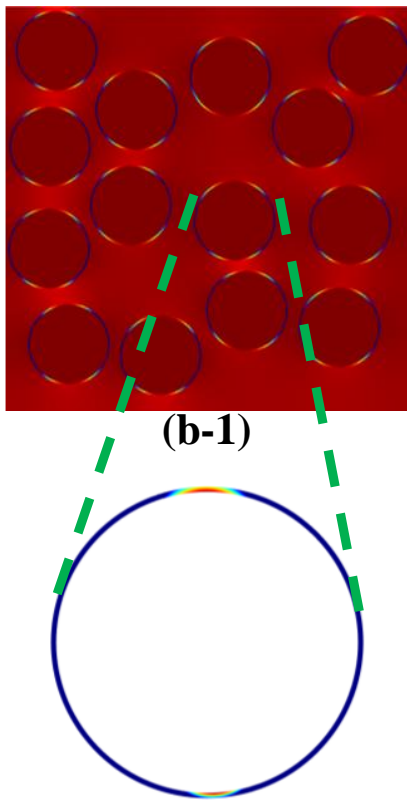

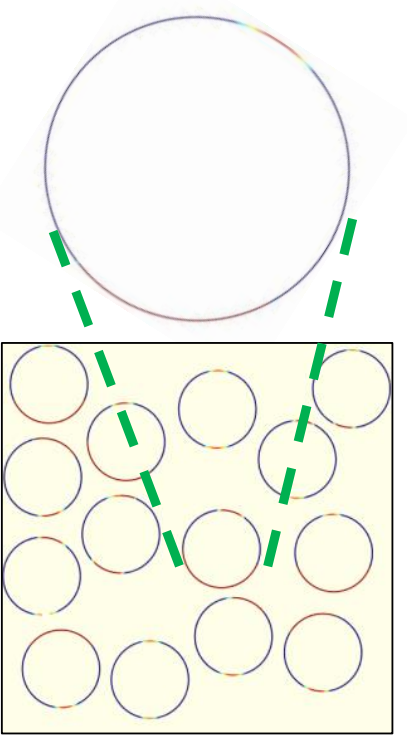

$(\mathbf{a}-2)$
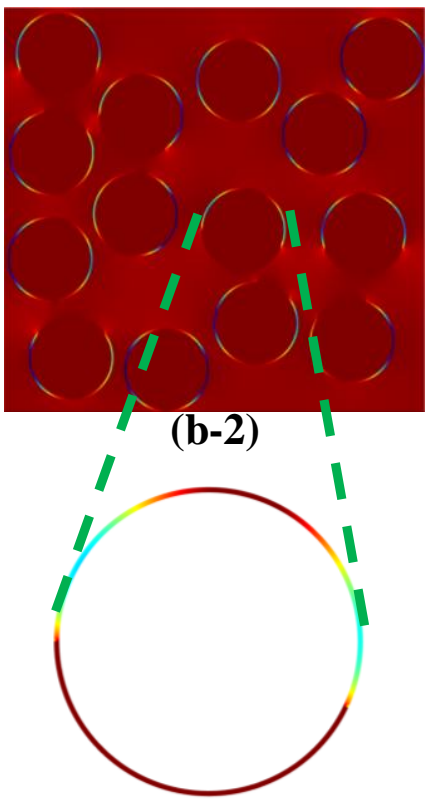

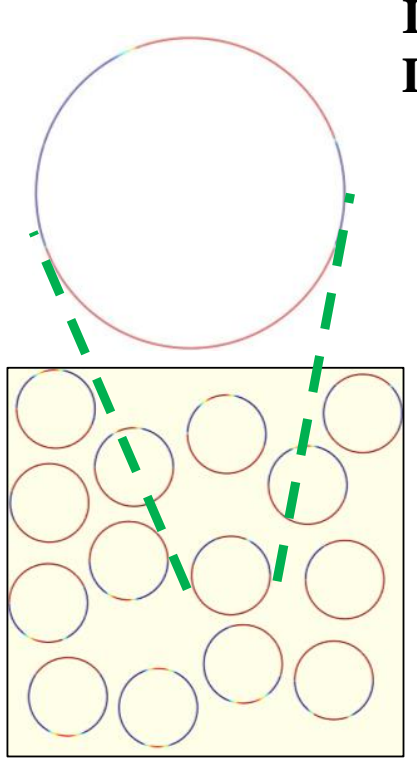

(a-3)

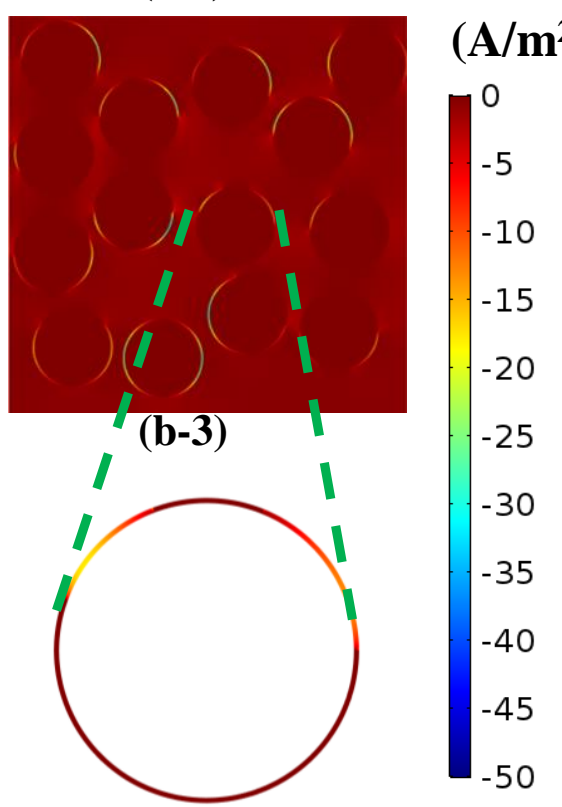

Figure 5. Influence of interfacial debonding on the electro-mechanical response: (a-1) interface damage parameter in the unit cell without any externally applied strain; interface damage parameter corresponding to applied strain of (a-2) $0.0075 \%$ and (a-3) 0.0161\%; (b-1) ECD along Y direction for applied unit electrical potential corresponding to: (b-1) undeformed unit cell, (b-2) unit cell under applied strain of $0.0075 \%$ and $(b-3)$ unit cell under applied strain of $0.0161 \%$

In order to evaluate the influence of debonding on the FCR, a dimensionless scalar parameter, fractional interface debonding is introduced which can be defined as the fraction of the total perimeter of inclusions that has de-bonded completely $\left(D_{c}=1\right)$. Figure 6 shows the fractional interface debonding and FCR with 
variation of applied strain. The fractional interface debonding increases progressively with increase in tensile strain. Consequently, the FCR also increases due to additional resistance in the unit cell imparted by the de-bonded interface which makes the associated fraction of conductive coating ineffective. With progressive interfacial debonding, the stress in the matrix increases due to lack of stress-transfer from the matrix to the stiffer inclusions. Finally, the stress in the matrix reaches its strength when the strain is increased beyond $0.0161 \%$ and the damage in the matrix is initiated. Beyond this point, fractional interface debonding remains almost constant and the progressive damage in the matrix becomes dominant. The influence of progressive matrix-damage on the FCR is elucidated in the forthcoming section with a view to evaluate the damage-sensing capability of this smart cementitious material.

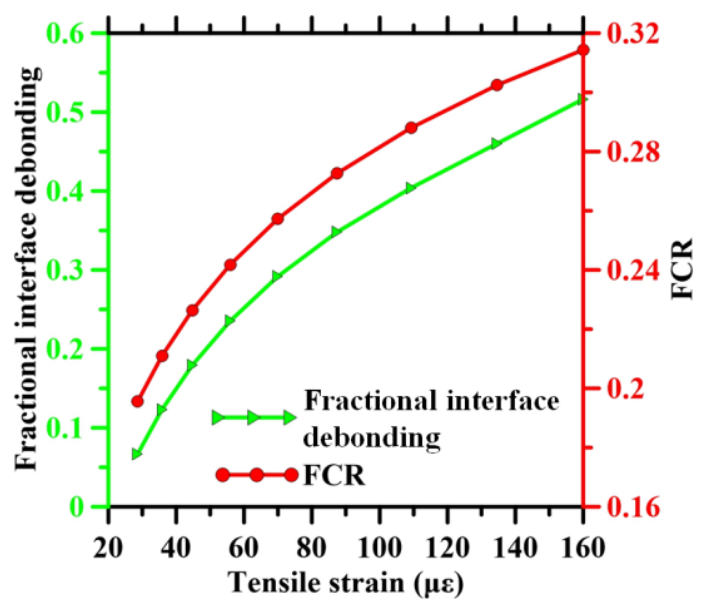

Figure 6: Fractional interface damage and FCR with varying tensile strain

\subsubsection{Influence of conductive coating on damage-sensing capability}

This section implements a continuum damage model, explained earlier (refer to section 2.2.3), in the HCP matrix of the mortar microstructure to evaluate the damage-sensing capability of the smart material in the post-peak regime. The model assumes isotropic stiffness degradation and it requires the parameters $\varepsilon_{D_{0}}, A_{t}, B_{t}, A_{c}$ and $B_{c}$ for HCP matrix as input (Equation 23). In the context of tensile damage, the values of the parameters $\varepsilon_{D_{0}}, A_{t}$ and $B_{t}$ for HCP matrix are $0.0001,1$ and 10000 respectively which are adopted from the literature [43]. The damage model parameters in ITZ are considered to be same as the HCP matrix due to lack of data. The continuum damage model is implemented using user defined subroutine in $\mathrm{ABAQUS}^{\mathrm{TM}}$ and the scalar damage variable, $\mathrm{D}$ (Equation 23) in the matrix is obtained.

To obtain the electrical responses, the damaged microstructure is re-meshed and imported to the electrical module where the electrical conductivity of damaged elements was modified proportional to 
the damage variable $D$ (Equation 24). Figures 7(a-1), (a-2) and (a-3) plot the values of the damage variable (D) under applied tensile strain of 161, 170 and $210 \mu \varepsilon$ respectively. While Figure 7 (a-1) doesn't show any damage in the matrix, Figures 7 (a-2), (a-3) show progressive damage in the matrix with increase in the applied strain in the post-peak regime. The extent of interfacial damage (debonding) remains almost same beyond applied strain of $161 \mu \varepsilon$. Figures 7(b-1), (b-2) and (b-3) show the influence of progressive matrixdamage (under applied tensile strain of 161,170 and $210 \mu \varepsilon$ respectively) on the electrical response. The general trend in the electrical responses suggest a decrease in the ECD with progressive damage.

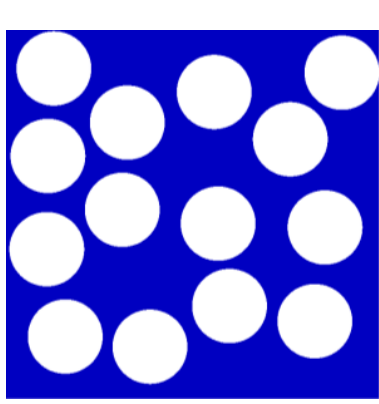

(a-1)

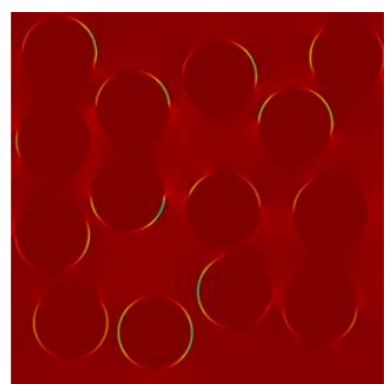

(b-1)

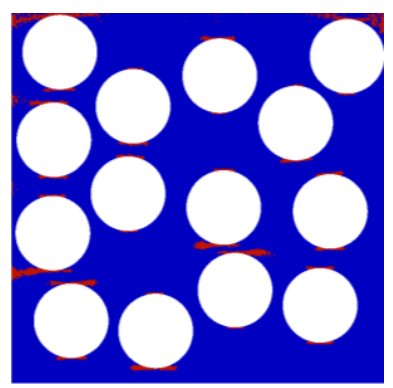

$(\mathbf{a}-2)$

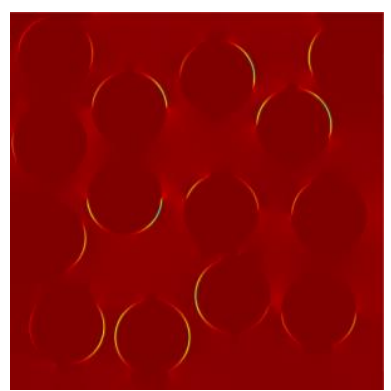

(b-2)

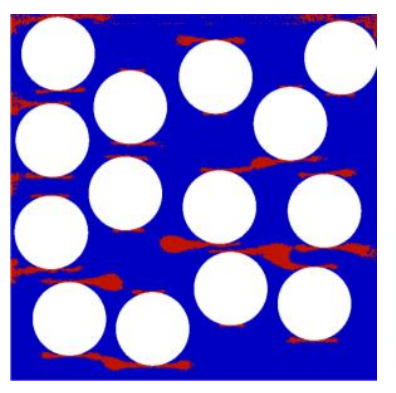

(a-3)

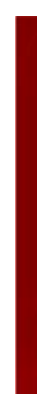

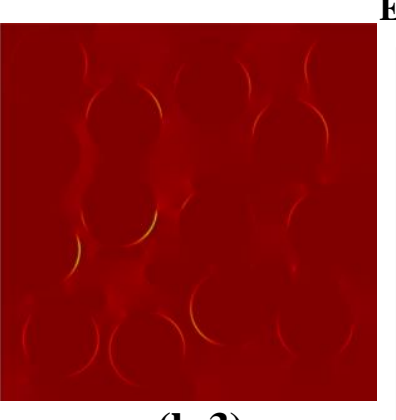

(b-3)

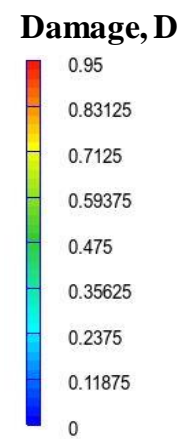

$\operatorname{ECD}_{\mathbf{Y}}\left(\mathbf{A} / \mathbf{m}^{2}\right)$

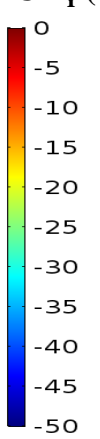

Figure 7: Progressive damage in HCP matrix corresponding to applied strain of (a-1)161 $\mu \varepsilon,(a-2) 170 \mu \varepsilon$ and $(a-3) 210 \mu \varepsilon ; E C D\left(A / m^{2}\right)$ in $Y$ direction in the unit cells corresponding to applied strain of: (b-1)161 $\mu \varepsilon,(b-2) 170 \mu \varepsilon$ and (b-3) $210 \mu \varepsilon$

In order to shed more light on the relationship between damage and electrical response, Figure 8 plots the overall variation of FCR and stress with increasing tensile strain. It can be observed clearly from Figure 8 that, the FCR increases almost linearly with increase in strain initially up to a tensile strain of approximately $25-30 \mu \varepsilon$ beyond which the relationship becomes non-linear due to onset of interfacial debonding. As the damage in matrix initiates (beyond the peak stress), the rate of increase in FCR with respect to increase in strain increases rapidly and the sudden jump represents the onset of damage in the matrix. Thus, the relationship, shown in Figure 8, substantiates the strain-sensing capability of the smart 
cementitious material in the pre-peak regime as well as damage sensing capability in the post-peak regime.

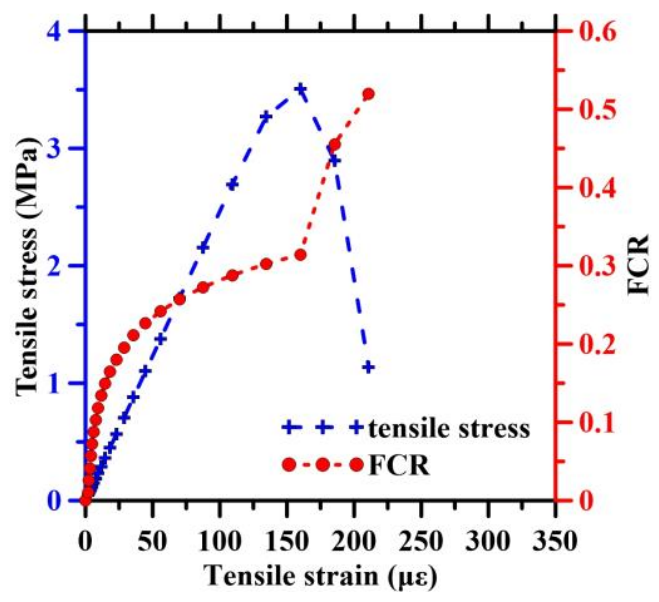

Figure 8. Progressive damage and FCR with increasing tensile strain

\subsubsection{Influence of thickness and electrical conductivity of the coating}

While the previous section highlighted the strain/damage sensing capability of the smart material, this section elucidates the influence of the electrical conductivity and thickness of the coating on the overall sensing efficiency. Figure 9(a) shows the influence of thickness of coating on the FCR while considering a constant electrical conductivity of $1000 \mathrm{~S} / \mathrm{m}$ for the coating $[63,64]$. The general trend suggests that the FCR increases with increase in coating thickness for all the applied strains although the rate of increase in FCR with respect to coating thickness decreases beyond a thickness of 12 microns, a phenomenon often observed in non-conductive matrices with conductive phases $[17,74]$. Almost insignificant amount of increase in FCR is observed when the thickness increased from 18 microns to 30 microns. From the simulations, it is clear that a thin conductive film of around 10-20 microns thickness is enough to obtain the efficiency required for strain-sensing in these materials. Figure $9(b)$ shows the influence of electrical conductivity of the coating of thickness 10 microns on the overall FCR of the smart material. Variation of CNT loading in the latex matrix leads to a change in overall conductivity of the MWCNT-latex film deposited on the sand. A wide range of values of conductivity have been reported in literature[63,74,75], the maximum being $1000 \mathrm{~S} / \mathrm{m}[63,64]$. An almost linearly increasing trend of FCR is observed with the increase in the coating conductivity which can be attributed to the increasing overall conductivity of the system due to increase in the volume fraction of conductive coating. Trends in both Figures 9(a) and (b) suggest a significant increase in FCR when the strain is increased from $27 \mu \varepsilon$ to $81 \mu \varepsilon$. This is attributed to the onset of interfacial debonding beyond $27 \mu \varepsilon$ which results in additional resistance and thereby 
increase in FCR as explainer earlier in this paper. The parametric variations indicate that the FCR is more sensitive to change in coating thickness as compared to change in conductivity of coating within bounds. FCR increased more than four-folds when the thickness of coating increased from 8 microns to 20 microns whereas a relatively smaller increase (about 60\%) in FCR was observed when the conductivity increased from 200 to $1000 \mathrm{~S} / \mathrm{m}$. Its significance lies in the fact that the experimental limitations of achieving higher coating conductivity with CNT loading [64] can be offset with the variation of thickness of such coatings to obtain a more sensitive overall system.

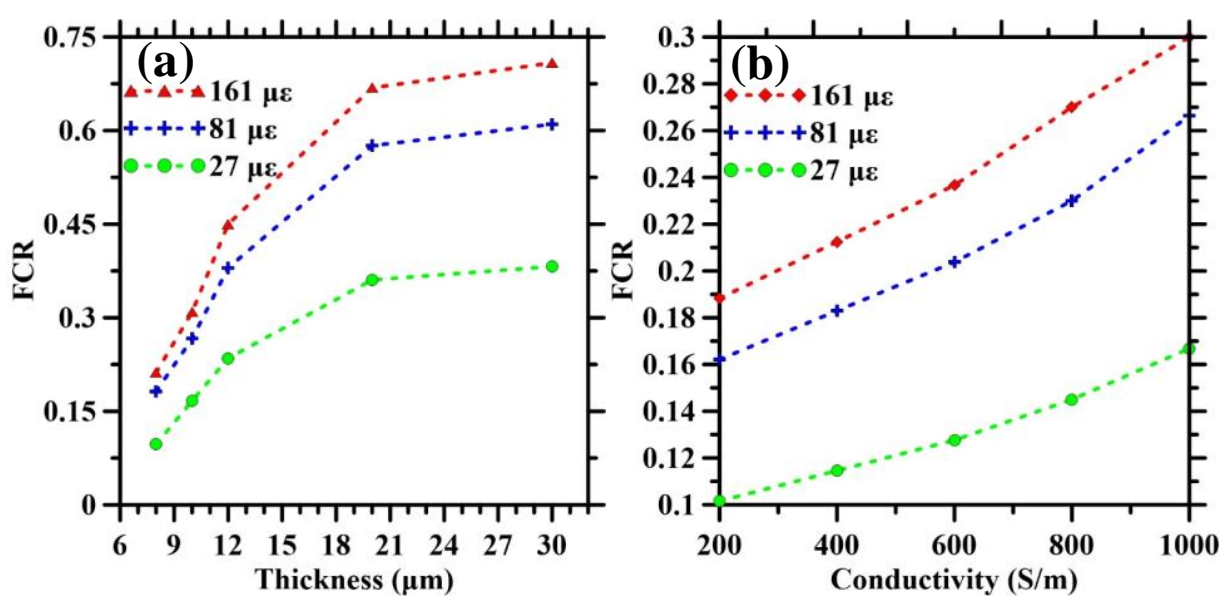

Figure 9. (a) Variation of FCR with varying coating-thickness; (b) relationship between FCR and the conductivity of the coating for different applied strains.

\subsection{Comparison of simulation results with experimental observations}

This section applies the numerical simulation framework to predict strain-sensing behavior of the smart cementitious material containing nano-engineered cement-aggregate interface under compression and compares the numerical simulation results with the experimental results reported in [16]. The mortar consists of $45 \%$ coated sand and the binder contains $25 \%$ ground granulated blast furnace slag (GGBFS) by weight as cement-replacement. The thickness of the conductive coating is 10 microns [15]. The material properties of sand, conductive coating and ITZ are reported in Table $1[15,51,56,59,63-67]$. The conductivity of the matrix is reduced by $20 \%$ owing to the presence of $25 \%$ GGBFS by weight $[76,77]$ whereas the values of Young's modulus and Poisson's ratio of the binder matrix are considered same as that of HCP [78]. Interfacial debonding is incorporated using traction-separation law defined by the parameters initial fracture energy $\left(\mathrm{G}_{f}\right)$, total fracture energy $\left(G_{\mathrm{F}}\right)$ and tensile strength of matrix $\left(f_{t}\right)$. Values of these parameters adopted in this simulation are considered same as the HCP matrix as reported earlier in the section 3.1.1. Here in case of compression, the tangent material matrix, shown in Equation 
18 , is used and the scalar interface damage parameter, $D_{c}$ is obtained in the matrix as well as in the ITZ. Isotropic damage under compression is incorporated using the parameters $\varepsilon_{D_{0}}, A_{c}$ and $B_{c}$. The values of these parameters used in this simulation are 0.0001, 1 and 10000 respectively [43]. The deformed/damaged unit cell is re-meshed and imported to the electrical module which computes electrical responses for varying strains as explained earlier in this paper.

Figure 10 compares the FCR values obtained from the simulation framework to the ones reported in an experimental study [16]. Figure 10(a) plots the simulation results considering only interfacial debonding without considering damage in the matrix. The simulated FCR values correspond well with the experimental measurements when the applied compressive strain is lower than approximately $0.16 \%$ whereas the simulated values diverge from the experimental observations at higher compressive strains. This can be attributed to the damage in the matrix which is not captured by the model. Figure 10 (b) shows the simulated FCR values when isotropic damage model in the matrix is incorporated in addition to interface damage. Upon implementation of continuum damage in the matrix, the high strain FCRs also match closely with the experimental measurements as can be seen in Figure 10(b). Incorporation of the isotropic damage enables significantly improved prediction of FCR in the post-peak regime thus verifying applicability of the current simulation framework towards prediction of strain-sensing and damagesensing capabilities of smart cementitious materials.
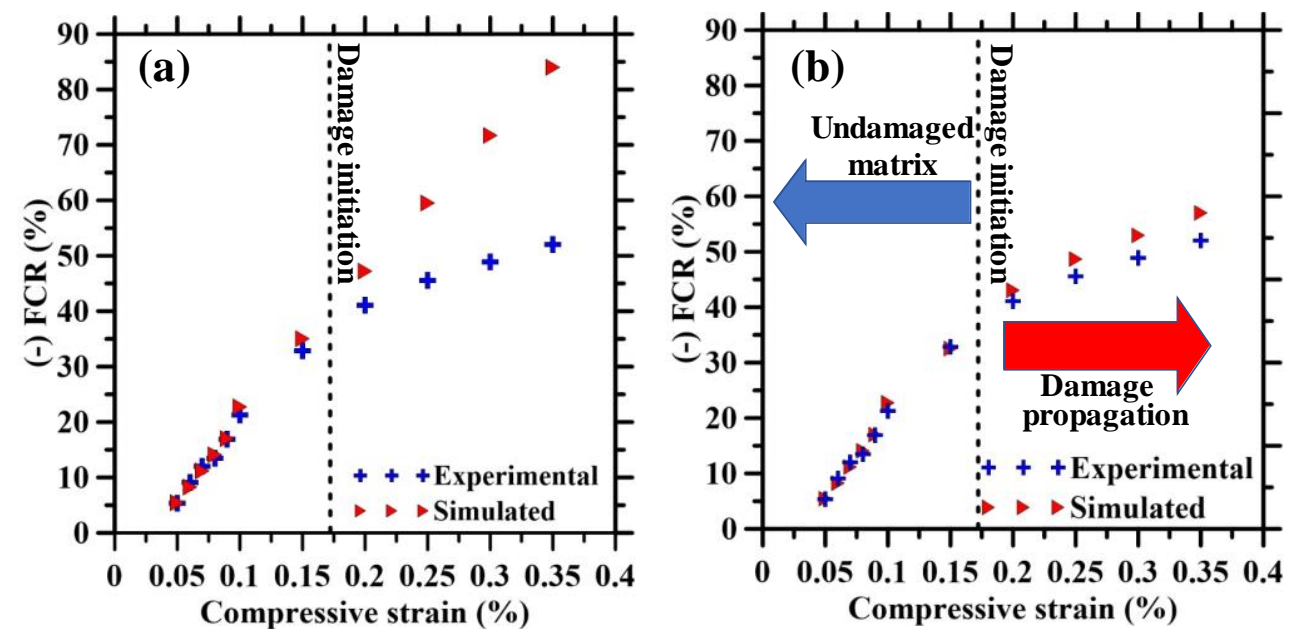

Figure 10. The simulated and experimental FCR with varying compressive strain: (a) The simulation does not consider damage in the matrix; (b) simulation incorporates isotropic damage in HCP matrix 


\section{CONCLUSIONS}

This paper presents a comprehensive numerical approach towards prediction of electro-mechanical response and strain-sensing capability of smart random heterogeneous materials. The framework first generates representative unit cell using Lubachevsky-Stillinger algorithm and the generated unit cell is imported into the mechanical module. The mechanical module applies periodic boundary conditions, meshes the unit cell, implements interfacial damage at the inclusion-matrix interface and incorporates isotropic damage in the matrix in the post-peak regime to obtain the deformed/damaged microstructure for any applied tensile or compressive strain. The deformed/damaged microstructure, obtained from the mechanical module, is imported into a remeshing subroutine that meshes the deformed/damaged unit cell and improves the quality of mesh for a better solution. The re-meshed unit cell is imported into the electrical module to obtain the electrical responses for the applied strain.

The applicability of the simulation framework is confirmed here through its successful implementation on a smart cementitious material containing nano-engineered conductive coating at the cement-aggregate interface. Representative microstructures of the smart cementitious material were first generated and the electro-mechanical responses were simulated using combined use of a mechanical module, remeshing module and electrical module. In the pre-peak regime, progressive interfacial debonding with increasing tensile strain resulted in significant progressive increase in FCR, signifying efficient strain-sensing capability of the material. With progressive interfacial debonding, the stress in the matrix kept on increasing and damage in the matrix was initiated in the matrix when the stress in the matrix exceeded the tensile strength. The onset of damage in the matrix was reflected in the form of significant jump in FCR, substantiating damage-sensing capability of the smart mortar. Parametric study with variations in thickness and conductivity of the coating revealed that limitations of achieving higher coating conductivity with increased CNT loadings [74] can be offset with the variation of thickness of such coatings to obtain a more sensitive overall system. The validation of the simulation approach presented here provides confidence on its capability to be implemented for various smart heterogeneous composites and it can help develop design strategies to tailor the microstructure for efficient performance.

\section{ACKNOWLEDGEMENTS}

The authors gratefully acknowledge the support from College of Engineering (COE) and Department of Civil and Environmental Engineering at the University of Rhode Island (URI) towards this study. 


\section{DATA AVAILABILITY}

The raw/processed data required to reproduce these findings cannot be shared at this time as the data also forms part of an ongoing study

\section{REFERENCES}

[1] C.R. Farrar, K. Worden, An introduction to structural health monitoring, Philosophical Transactions of the Royal Society of London A: Mathematical, Physical and Engineering Sciences. 365 (2007) 303-315.

[2] S.W. Doebling, C.R. Farrar, M.B. Prime, A Summary Review of Vibration-Based Damage Identification Methods, The Shock and Vibration Digest. 30 (1998) 91-105.

[3] Y.Y. Lim, S. Bhalla, C.K. Soh, Structural identification and damage diagnosis using self-sensing piezoimpedance transducers, Smart Mater. Struct. 15 (2006) 987.

[4] W. Yan, J.B. Cai, W.Q. Chen, Monitoring interfacial defects in a composite beam using impedance signatures, Journal of Sound and Vibration. 326 (2009) 340-352.

[5] W. Yan, W.Q. Chen, Structural Health Monitoring Using High-Frequency Electromechanical Impedance Signatures, Advances in Civil Engineering. (2010). https://www.hindawi.com/journals/ace/2010/429148/abs/ (accessed August 14, 2018).

[6] S. Bhalla, A. Gupta, S. Bansal, T. Garg, Ultra Low-cost Adaptations of Electro-mechanical Impedance Technique for Structural Health Monitoring, Journal of Intelligent Material Systems and Structures. 20 (2009) 991-999.

[7] S. Zhu, D.D.L. Chung, Analytical model of piezoresistivity for strain sensing in carbon fiber polymermatrix structural composite under flexure, Carbon. 45 (2007) 1606-1613.

[8] S. Wen, D.D.L. Chung, Model of piezoresistivity in carbon fiber cement, Cement and Concrete Research. 36 (2006) 1879-1885.

[9] S. Wen, D.D.L. Chung, A comparative study of steel-and carbon-fibre cement as piezoresistive strain sensors, Advances in Cement Research. 15 (2003) 119-128.

[10] S. Wen, D.D.L. Chung, Piezoresistivity in continuous carbon fiber cement-matrix composite, Cement and Concrete Research. 29 (1999) 445-449.

[11] X. Wang, D.D.L. Chung, Short carbon fiber reinforced epoxy coating as a piezoresistive strain sensor for cement mortar, Sensors and Actuators A: Physical. 71 (1998) 208-212.

[12] S. Wang, D.D.L. Chung, Piezoresistivity in continuous carbon fiber polymer-matrix composite, Polymer Composites. 21 (2000) 13-19.

[13] D.D.L. Chung, Piezoresistive cement-based materials for strain sensing, Journal of Intelligent Material Systems and Structures. 13 (2002) 599-609.

[14] P.-W. Chen, D.D. Chung, Carbon fiber reinforced concrete for smart structures capable of nondestructive flaw detection, Smart Materials and Structures. 2 (1993) 22.

[15] L.P. Mortensen, D.H. Ryu, Y.J. Zhao, K.J. Loh, Rapid Assembly of Multifunctional Thin Film Sensors for Wind Turbine Blade Monitoring, Key Engineering Materials. (2013). https://www.scientific.net/KEM.569-570.515 (accessed August 14, 2018).

[16] K.J. Loh, J. Gonzalez, Cementitious Composites Engineered with Embedded Carbon Nanotube Thin Films for Enhanced Sensing Performance, J. Phys.: Conf. Ser. 628 (2015) 012042.

[17] B.M. Lee, K.J. Loh, Carbon nanotube thin film strain sensors: comparison between experimental tests and numerical simulations, Nanotechnology. 28 (2017) 155502. 
[18] X. Wang, D.D.L. Chung, Short-carbon-fiber-reinforced epoxy as a piezoresistive strain sensor, Smart Materials and Structures. 4 (1995) 363.

[19] S. Das, A. Maroli, N. Neithalath, Micromechanical Modeling for Material Design of Durable Infrastructural Materials: The Influence of Aggregate and Matrix Modification on Elastic Behavior of Mortars, in: International Conference on Durability of Concrete Structures, 2016.

[20] D.S. Van, P.J.G. Schreurs, W.A.M. Brekelmans, H.E.H. Meijer, Overall behaviour of heterogeneous elastoviscoplastic materials: Effect of microstructural modelling, Mechanics of Materials. 32 (2000) 449-462. doi:10.1016/S0167-6636(00)00019-3.

[21] P. Raghavan, S. Ghosh, A continuum damage mechanics model for unidirectional composites undergoing interfacial debonding, Mechanics of Materials. 37 (2005) 955-979.

[22] S. Li, Boundary conditions for unit cells from periodic microstructures and their implications, Composites Science and Technology. 68 (2008) 1962-1974.

[23] Z. Xia, C. Zhou, Q. Yong, X. Wang, On selection of repeated unit cell model and application of unified periodic boundary conditions in micro-mechanical analysis of composites, International Journal of Solids and Structures. 43 (2006) 266-278.

[24] S. Gupta, J.G. Gonzalez, K.J. Loh, Self-sensing concrete enabled by nano-engineered cementaggregate interfaces, Structural Health Monitoring. 16 (2017) 309-323.

[25] P. Wriggers, S.O. Moftah, Mesoscale models for concrete: Homogenisation and damage behaviour, Finite Elements in Analysis and Design. 42 (2006) 623-636.

[26] J. Mazars, A description of micro- and macroscale damage of concrete structures, Engineering Fracture Mechanics. 25 (1986) 729-737.

[27] J. Mazars, G. Pijaudier-Cabot, Continuum Damage Theory-Application to concrete, Journal of Engineering Mechanics. 115 (1989).

[28] A. Benallal, R. Billardon, I. Doghri, An integration algorithm and the corresponding consistent tangent operator for fully coupled elastoplastic and damage equations, Communications in Applied Numerical Methods. 4 (1988) 731-740.

[29] J. Lemaitre, R. Desmorat, M. Sauzay, Anisotropic damage law of evolution, European Journal of Mechanics - A/Solids. 19 (2000) 187-208.

[30] Abaqus 6.14 Documentation, (2014). http://abaqus.software.polimi.it/v6.14/index.html (accessed May 25, 2018).

[31] B.D. Lubachevsky, F.H. Stillinger, E.N. Pinson, Disks vs. spheres: Contrasting properties of random packings, Journal of Statistical Physics. 64 (1991) 501-524.

[32] B.D. Lubachevsky, F.H. Stillinger, Geometric properties of random disk packings, Journal of Statistical Physics. 60 (1990) 561-583.

[33] S. Das, A. Maroli, S.S. Singh, T. Stannard, X. Xiao, N. Chawla, N. Neithalath, A microstructure-guided constitutive modeling approach for random heterogeneous materials: Application to structural binders, Computational Materials Science. 119 (2016) 52-64.

[34] H.A. Meier, E. Kuhl, P. Steinmann, A note on the generation of periodic granular microstructures based on grain size distributions, International Journal for Numerical and Analytical Methods in Geomechanics. 32 (2008) 509-522.

[35] K. Mohsen, A.G. Straatman, A thermal periodic boundary condition for heating and cooling processes, International Journal of Heat and Fluid Flow. 28 (2007) 329-339.

[36] J. Sanahuja, C. Toulemonde, Numerical homogenization of concrete microstructures without explicit meshes, Cement and Concrete Research. 41 (2011) 1320-1329.

[37] S. Das, P. Yang, S.S. Singh, J.C.E. Mertens, X. Xiao, N. Chawla, N. Neithalath, Effective properties of a fly ash geopolymer: Synergistic application of X-ray synchrotron tomography, nanoindentation, and homogenization models, Cement and Concrete Research. 78 (2015) 252-262. 
[38] S. Das, M. Aguayo, S.D. Rajan, G. Sant, N. Neithalath, Microstructure-guided numerical simulations to predict the thermal performance of a hierarchical cement-based composite material, Cement and Concrete Composites. 87 (2018) 20-28.

[39] M. Kolluri, J.P.M. Hoefnagels, J.A.W. van Dommelen, M.G.D. Geers, Irreversible mixed mode interface delamination using a combined damage-plasticity cohesive zone enabling unloading, Int J Fract. 185 (2014) 77-95.

[40] G. Alfano, E. Sacco, Combining interface damage and friction in a cohesive-zone model, International Journal for Numerical Methods in Engineering. 68 (2006) 542-582.

[41] M. Ortiz, A. Pandolfi, Finite-deformation irreversible cohesive elements for three-dimensional crack-propagation analysis, International Journal for Numerical Methods in Engineering. 44 (1999) 1267-1282.

[42] R.A. Day, D.M. Potts, Zero thickness interface elements - numerical stability and application, International Journal for Numerical and Analytical Methods in Geomechanics. 18 (1994) 689-708.

[43] T. Wu, P. Wriggers, Multiscale diffusion-thermal-mechanical cohesive zone model for concrete, Computational Mechanics. 55 (2015) 999-1016.

[44] D.S. Dugdale, Yielding of steel sheets containing slits, Journal of the Mechanics and Physics of Solids. 8 (1960) 100-104.

[45] M. Elices, C. Rocco, C. Roselló, Cohesive crack modelling of a simple concrete: Experimental and numerical results, Engineering Fracture Mechanics. 76 (2009) 1398-1410.

[46] V. Tvergaard, Cohesive zone representations of failure between elastic or rigid solids and ductile solids - ScienceDirect, Engineering Fracture Mechanics. 70 (2003) 1859-1868.

[47] J. Roesler, G.H. Paulino, K. Park, Concrete fracture prediction using bilinear softening ScienceDirect, Cement and Concrete Composites. 29 (2007) 300-312.

[48] M. Koniorczyk, D. Gawin, B.A. Schrefler, Modeling evolution of frost damage in fully saturated porous materials exposed to variable hygro-thermal conditions, Computer Methods in Applied Mechanics and Engineering. 297 (2015) 38-61.

[49] J. Mazars, G. Pijaudier-Cabot, From damage to fracture mechanics and conversely: A combined approach, International Journal of Solids and Structures. 33 (1996) 3327-3342.

[50] I. Özdemir, W. a. M. Brekelmans, M.G.D. Geers, A Thermo-mechanical cohesive zone model, Comput Mech. 46 (2010) 735-745.

[51] P. Yang, S. Chowdhury, N. Neithalath, Strain sensing ability of metallic particulate reinforced cementitious composites: Experiments and microstructure-guided finite element modeling, Cement and Concrete Composites. 90 (2018) 225-234.

[52] B.R. Loyola, V.L. Saponara, K.J. Loh, T.M. Briggs, G. O’Bryan, J.L. Skinner, Spatial Sensing Using Electrical Impedance Tomography, IEEE Sensors Journal. 13 (2013) 2357-2367.

[53] B.R. Loyola, T.M. Briggs, L. Arronche, K.J. Loh, V. La Saponara, G. O’Bryan, J.L. Skinner, Detection of spatially distributed damage in fiber-reinforced polymer composites, Structural Health Monitoring. 12 (2013) 225-239.

[54] Y. Ding, Z. Han, Y. Zhang, C.M. Azevedo, Hybrid use of steel and carbon-fiber reinforced concrete for monitoring of crack behavior, in: ECCM15 - 15th European Conference on Composite Materials, European Conference on Composite Materials (ECCM), 2012.

[55] B.D. Lubachevsky, How to simulate billiards and similar systems, Journal of Computational Physics. 94 (1991) 255-283.

[56] S. Das, A. Maroli, N. Neithalath, Finite element-based micromechanical modeling of the influence of phase properties on the elastic response of cementitious mortars, Construction and Building Materials. 127 (2016) 153-166.

[57] J.P. Ollivier, J.C. Maso, B. Bourdette, Interfacial transition zone in concrete, Advanced Cement Based Materials. 2 (1995) 30-38. 
[58] D.P. Bentz, Influence of internal curing using lightweight aggregates on interfacial transition zone percolation and chloride ingress in mortars, Cement and Concrete Composites. 31 (2009) 285-289.

[59] F. Grondin, M. Matallah, How to consider the Interfacial Transition Zones in the finite element modelling of concrete?, Cement and Concrete Research. 58 (2014) 67-75.

[60] D.L. Logan, A first course in the finite element method, Cengage Learning, 2011.

[61] J.E. Akin, Finite element analysis with error estimators: An introduction to the FEM and adaptive error analysis for engineering students, Elsevier, 2005.

[62] M. Okereke, S. Keates, Finite Element Applications: A Practical Guide to the FEM Process, Springer, 2018.

[63] J. Yu, K. Lu, E. Sourty, N. Grossiord, C.E. Koning, J. Loos, Characterization of conductive multiwall carbon nanotube/polystyrene composites prepared by latex technology, Carbon. 45 (2007) 28972903.

[64] N. Grossiord, J. Loos, L. Laake, High-Conductivity Polymer Nanocomposites Obtained by Tailoring the Characteristics of Carbon Nanotube Fillers, Advanced Functional Materials. 18 (2008) 32263234.

[65] B. Safadi, R. Andrews, E.A. Grulke, Multiwalled carbon nanotube polymer composites: Synthesis and characterization of thin films, Journal of Applied Polymer Science. 84 (2002) 2660-2669.

[66] J.N. Coleman, U. Khan, W.J. Blau, Y.K. Gun'ko, Small but strong: A review of the mechanical properties of carbon nanotube-polymer composites, Carbon. 44 (2006) 1624-1652.

[67] H. Jain, A.S. Nowick, Electrical conductivity of synthetic and natural quartz crystals, Journal of Applied Physics. 53 (1982) 477-484.

[68] K.M. Lee, J.H. Park, A numerical model for elastic modulus of concrete considering interfacial transition zone, Cement and Concrete Research. 38 (2008) 396-402.

[69] E.J. Garboczi, L.M. Schwartz, D.P. Bentz, Modeling the influence of the interfacial zone on the DC electrical conductivity of mortar, Advanced Cement Based Materials. 2 (1995) 169-181.

[70] J.D. Shane, T.O. Mason, H.M. Jennings, E.J. Garboczi, D.P. Bentz, Effect of the Interfacial Transition Zone on the Conductivity of Portland Cement Mortars, Journal of the American Ceramic Society. 83 (2000) 1137-1144.

[71] M.G.A. Tijssens, L.J. Sluys, E. van der Giessen, Simulation of fracture of cementitious composites with explicit modeling of microstructural features, Engineering Fracture Mechanics. 68 (2001) 1245-1263.

[72] P. Padevět, O. Zobal, Changes of the Fracture Energy of Cement Paste with Addition of Fly Ash in Time, Procedia Engineering. 48 (2012) 513-519. doi:10.1016/j.proeng.2012.09.547.

[73] M. Jebli, F. Jamin, E. Malachanne, E. Garcia-Diaz, M.S. El Youssoufi, Experimental characterization of mechanical properties of the cement-aggregate interface in concrete, Construction and Building Materials. 161 (2018) 16-25. doi:10.1016/j.conbuildmat.2017.11.100.

[74] P. Xie, P. Gu, J.J. Beaudoin, Electrical percolation phenomena in cement composites containing conductive fibres, Journal of Materials Science. 31 (1996) 4093-4097.

[75] W. Bauhofer, J.Z. Kovacs, A review and analysis of electrical percolation in carbon nanotube polymer composites, Composites Science and Technology. 69 (2009) 1486-1498.

[76] M.N. Soutsos, J.H. Bungey, S.G. Millard, M.R. Shaw, A. Patterson, Dielectric properties of concrete and their influence on radar testing, NDT \& E International. 34 (2001) 419-425.

[77] W.J. McCarter, G. Starrs, T.M. Chrisp, Electrical conductivity, diffusion, and permeability of Portland cement-based mortars, Cement and Concrete Research. 30 (2000) 1395-1400.

[78] G. Menéndez, V. Bonavetti, E.F. Irassar, Strength development of ternary blended cement with limestone filler and blast-furnace slag, Cement and Concrete Composites. 25 (2003) 61-67. doi:10.1016/S0958-9465(01)00056-7. 